\title{
Edoxaban and amiodarone: interactions on multiple levels
}

\section{David Conen*}

Division of Internal Medicine, Department of Medicine and Cardiovascular Research Institute Basel, University Hospital, Basel, Switzerland

\author{
This paper was guest edited by Anthony N. DeMaria, M.D. (University of California; ademaria@ucsd.edu).
}

\author{
This editorial refers to 'Edoxaban vs. warfarin in patients \\ with atrial fibrillation on amiodarone: a subgroup analysis

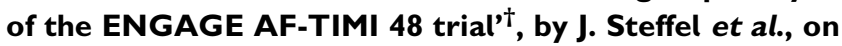 \\ page 2239.
}

Stroke prevention using oral anticoagulation is a highly effective intervention to improve outcomes among patients with atrial fibrillation (AF), the most common cardiac arrhythmia in the population. ${ }^{1,2}$ Compared with placebo, the use of vitamin $\mathrm{K}$ antagonists reduces the risk of stroke by $64 \%$ in patients with $A F$, but significantly increases the risk of major and life-threatening bleeding. ${ }^{3}$ In recent years, new oral anticoagulants with a more favourable risk-benefit profile have been developed and tested in large randomized trials, further improving anticoagulation treatment among patients with AF.

One of these studies was the Effective Anticoagulation with Factor Xa Next Generation in Atrial Fibrillation-Thrombolysis in Myocardial Infarction 48 (ENGAGE AF-TIMI 48) trial, a large randomized trial comparing the efficacy and safety of two dosing regimens of edoxaban with warfarin among AF patients at increased risk of stroke. Compared with warfarin, this trial established the noninferiority of both regimens with regard to prevention of stroke and systemic embolism, with the advantage of significantly lower rates of major bleeding associated with both dosing strategies. ${ }^{4}$ However, the low-dose edoxaban strategy was associated with a highly significant $41 \%$ increased risk of ischemic stroke, making the clinical use of this regimen less straightforward, despite its profound reduction of bleeding complications and a significant reduction in all-cause mortality.

Thus interventions to improve the efficacy of the low-dose edoxaban strategy without compromising too much its safety could have an important impact on clinical practice.

Drug-drug interactions that moderately increase edoxaban drug concentrations may help to achieve this goal. In this issue of the journal, a subgroup analysis of the ENGAGE AF-TIMI 48 trial is presented that investigated the effect of amiodarone, a widely used antiarrhythmic drug with multiple drug-drug interactions, on the efficacy and safety of edoxaban for stroke prevention in AF patients. ${ }^{5}$ The authors of this study showed that among the 2492 participants (11.8\%) receiving amiodarone at baseline, low-dose edoxaban was associated with a significant reduction in the risk of stroke or systemic embolism [hazard ratio (HR) $0.60,95 \%$ confidence interval $(\mathrm{Cl}) 0.36,0.99]$, without increasing the risk of ischemic stroke (HR 0.96, 95\% Cl 0.54, 1.70). In contrast, the risk of stroke or systemic embolism was significantly higher among patients in the low-dose edoxaban arm not taking amiodarone (HR 1.20, 95\% Cl 1.03, 1.40; $P$-value for interaction 0.01). On the other hand, the principal safety endpoint of major bleeding was similar among patients taking or not taking amiodarone ( $\mathrm{HR} 0.35,95 \% \mathrm{Cl}$ $0.21,0.59$ and $\mathrm{HR} 0.53,95 \% \mathrm{Cl} 0.46,0.61$; $P$-value for interaction 0.13). As expected, concomitant use of amiodarone increased edoxaban concentrations in the low-dose arm $(27.3 \pm 24.5 \mathrm{ng} / \mathrm{mL}$ vs. $21.9 \pm 20.8 \mathrm{ng} / \mathrm{mL}, P<0.001)$ and in the high-dose arm $(58.5 \pm 53.2 \mathrm{ng} / \mathrm{ml}$ vs. $43.2 \pm 41.1 \mathrm{ng} / \mathrm{mL}, P<0.001)$.

Now the key question is whether concomitant use of amiodarone and low-dose edoxaban achieves a "sweet spot" between protection from ischemic events and bleeding, as suggested by the authors, or whether the observed findings can be explained by chance. In my view, the second option is more likely for several reasons. First, as appropriately stated by the authors, study participants were not randomized to amiodarone treatment, and the amiodarone subgroup was relatively small and only one of several subgroups that were assessed, such that chance, bias or confounding may have contributed to these differential findings. Second, the significant interaction in efficacy in the low-dose edoxaban group was not observed in the high-dose group despite a larger difference in edoxaban concentrations between amiodarone users and non-users. In addition, co-administration of amiodarone had no effect on the incidence of major bleeding events, the principal safety endpoint. The authors hypothesize that the increase in plasma levels caused by co-administration of amiodarone and low-dose edoxaban occurs at an inflection point in the dose-response curve for efficacy but falls within the flatter part of the dose-response curve for bleeding, while the increase in concentration in high-dose edoxaban patients taking amiodarone occurs during the flat portion of the dose-

The opinions expressed in this article are not necessarily those of the Editors of the European Heart Journal or of the European Society of Cardiology.

† doi:10.1093/eurheartj/ehv201.

*Corresponding author. Department of Medicine, University Hospital, Petersgraben 4, 4031 Basel, Switzerland. Tel: +41 61 265 2525, Fax: +41 61 265 5734, E-mail: david.conen@usb.ch Published on behalf of the European Society of Cardiology. All rights reserved. (C) The Author 2015. For permissions please email: journals.permissions@oup.com. 
response curve for efficacy. While appealing, this hypothesis seems not to be consistent with the findings of a recently published paper from the ENGAGE AF-TIMI 48 trial, where there was a linear doseresponse curve for both efficacy and safety across a wide range of edoxaban concentrations, without evidence of an inflection point or saturation effect. ${ }^{6}$ In this analysis, the dose-response curve for bleeding was actually steeper than that for stroke or systemic embolism, suggesting that a relevant effect of amiodarone should have been observed primarily for the bleeding endpoint. Third, while differences in edoxaban concentrations were statistically significant, they were rather small on an absolute scale. Being on highdose vs. low-dose edoxaban had a far greater impact on edoxaban concentrations than being on amiodarone vs. no amiodarone as indicated above. Nevertheless, differences in the absolute rates of the primary endpoint among those taking and not taking amiodarone in the low-dose arm (1.12\% per year vs. $2.16 \%$ per year) are on the same order of magnitude as those between the $60-\mathrm{mg}$ dose and the $15-\mathrm{mg}$ dose (1.0\% per year vs. $2.36 \%$ per year), where differences in mean edoxaban concentrations were far greater (48.5 vs. $16.0 \mathrm{ng} / \mathrm{mL}){ }^{6}$

Nonetheless, the current article is still of clinical importance for several reasons. First, it shows that co-prescription of amiodarone does not have any visible adverse effects on the efficacy and safety of edoxaban. This is a very reassuring finding for those AF patients who need both amiodarone and effective stroke prevention. Although post-marketing studies are usually not randomized and therefore subject to bias, they will be an important tool to further increase our reassurance of edoxaban use in clinical practice, as has been nicely shown for dabigatran. ${ }^{7}$ Second, although the interaction between edoxaban and amiodarone seems to be less of an issue, the current article still highlights the importance of taking into account drug-drug interactions in clinical practice. While the novel oral anticoagulants have fewer interactions than vitamin $\mathrm{K}$ antagonists, we cannot ignore this important issue when prescribing these drugs to patients who often have several co-morbidities and comedications. ${ }^{8}$ Finally, this article nicely illustrates the challenges we face in the translation of trial findings to everyday patient care. If the interpretation of interaction $P$-values and subgroup effects remains difficult and controversial despite the availability of a large randomized trial in a well-characterized patient population, then finding the right drug for an individual patient is an even more daunting task. Only with carefully performed analyses from large studies such as ENGAGE AF-TIMI 48 we will be able to make the right decisions for our patients with whom we interact every day in clinical practice.

Conflict of interest: D.C. has received research grants from Bayer, Daiichi-Sankyo and BMS/Pfizer and scientific advisory boards fees from Bayer, Daiichi-Sankyo, BMS/Pfizer and Boehringer Ingelheim.

\section{References}

1. Conen D, Chae CU, Glynn RJ, Tedrow UB, Everett BM, Buring JE, Albert CM. Risk of death and cardiovascular events in initially healthy women with new-onset atrial fibrillation. JAMA 2011;305:2080-2087.

2. Krijthe BP, Kunst A, Benjamin EJ, Lip GY, Franco OH, Hofman A, Witteman JC, Stricker $\mathrm{BH}$, Heeringa J. Projections on the number of individuals with atrial fibrillation in the European Union, from 2000 to 2060. Eur Heart J 2013;34:2746-2751.

3. Hart RG, Pearce LA, Aguilar MI. Meta-analysis: antithrombotic therapy to prevent stroke in patients who have nonvalvular atrial fibrillation. Ann Intern Med 2007; 146:857-867.

4. Giugliano RP, Ruff CT, Braunwald E, Murphy SA, Wiviott SD, Halperin JL, Waldo AL, Ezekowitz MD, Weitz Jl, Spinar J, Ruzyllo W, Ruda M, Koretsune Y, Betcher J, Shi M, Grip LT, Patel SP, Patel I, Hanyok JJ, Mercuri M, Antman EM, Investigators EA-T. Edoxaban versus warfarin in patients with atrial fibrillation. N Engl J Med 2013; 369:2093-2104.

5. Steffel J, Giugliano RP, Braunwald E, Murphy SA, Atar D, Heidbuchel H, Camm AJ, Antman EM, Ruff CT. Edoxaban vs. warfarin in patients with atrial fibrillation on amiodarone: a subgroup analysis of the ENGAGE AF-TIMI 48 trial. Eur Heart J 2015;36:2239-2245

6. Ruff CT, Giugliano RP, Braunwald E, Morrow DA, Murphy SA, Kuder JF, Deenadayalu N, Jarolim P, Betcher J, Shi M, Brown K, Patel I, Mercuri M, Antman EM. Association between edoxaban dose, concentration, anti-Factor $\mathrm{Xa}$ activity, and outcomes: an analysis of data from the randomised, double-blind ENGAGE AF-TIMI 48 trial. Lancet 2015;385:2288-2295.

7. Graham DJ, Reichman ME, Wernecke M, Zhang R, Southworth MR, Levenson M, Sheu TC, Mott K, Goulding MR, Houstoun M, MaCurdy TE, Worrall C, Kelman JA. Cardiovascular, bleeding, and mortality risks in elderly Medicare patients treated with dabigatran or warfarin for nonvalvular atrial fibrillation. Circulation 2015; 131:157-164.

8. Heidbuchel H, Verhamme P, Alings M, Antz M, Hacke W, Oldgren J, Sinnaeve P, Camm AJ, Kirchhof P, European Heart Rhythm Association. European Heart Rhythm Association practical guide on the use of new oral anticoagulants in patients with non-valvular atrial fibrillation. Europace 2013;15:625-651. 